\title{
Effects of an App-Based Physical Exercise Program on Selected Parameters of Physical Fitness of Females in Retirement: A Randomized Controlled Trial
}

\author{
Sonja Jungreitmayr ${ }^{1 *}$, Christina Kranzinger ${ }^{2}$, Verena Vene ${ }^{2}$ and Susanne Ring-Dimitriou ${ }^{1}$ \\ 'Department of Sport and Exercise Science, Paris Lodron University of Salzburg, Salzburg, Austria, ${ }^{2}$ Salzburg Research \\ Forschungsgesellschaft mbH, Salzburg, Austria
}

OPEN ACCESS

Edited by:

Achraf Ammar,

Johannes Gutenberg University

Mainz, Germany

Reviewed by:

Fabian Herold,

German Center for

Neurodegeneratives, Helmholtz

Association of German Research

Centers (HZ), Germany

Bernhard Grässler,

Otto von Guericke University

Magdeburg, Germany

*Correspondence:

Sonja Jungreitmayr

sonja.jungreitmayr@plus.ac.at

Specialty section:

This article was submitted to Interdisciplinary Physics, a section of the journal

Frontiers in Physics

Received: 24 November 2021 Accepted: 11 February 2022

Published: 04 March 2022

Citation:

Jungreitmayr $S$, Kranzinger $C$, Venek V and Ring-Dimitriou S (2022)

Effects of an App-Based Physical

Exercise Program on Selected

Parameters of Physical Fitness of

Females in Retirement: A

Randomized Controlled Trial.

Front. Physiol. 13:821773.

doi: 10.3389/fphys.2022.821773
Modern technologies enable new options in the delivery of physical exercise programs. Specially designed app-based programs can be used to help older people in particular to integrate physical exercise into their daily lives. This study examines the influence of an app-based physical exercise program on selected parameters of physical fitness, such as muscular strength, balance, and flexibility. The women $(n=110)$ were on average 65.3 $( \pm 1.5)$ years old and, compared to age-specific norm values, healthy. The 14-week intervention consisted of an app-based, unsupervised physical exercise program, in which the exercise frequency and duration of sessions were self-selected. The physical exercise program consisted of simple, functional exercises such as arm circles, squats, lateral raises. The participants were provided with an elastic resistance band and an exercise ball allowing them to increase exercise intensity if needed. Participants were randomly assigned to intervention group (IG) and control group (CG). $71 \%$ of the IG used the physical exercise program at least 1.2 times per week, whereas $25 \%$ of the IG showed usage rates above four times per week. Significant effects were found in the domains of muscular strength and flexibility. While IG could maintain their performance in isometric muscular strength tests and increased their flexibility, CG faced a decrease in those parameters. Thus, this app-based physical exercise program had positively influenced muscular strength and flexibility in women over 60 years of age.

Keywords: active aging, digital, strength, AAL, healthy aging, flexibility

\section{INTRODUCTION}

The large number of baby boomers is approaching the retirement age (Knickman and Snell, 2002) and demographic trends are leading Europe to an increasingly aging society (Grundy and Murphy, 2017). In conjunction with the general increase in life expectancy, this leads to an increase in the total number of people of advanced age. More precisely, the group of people aged 65 and over is the only one that is expected to grow in the European region (Lutz et al., 2018). Notably, this age group is at risk of physical decline if no countermeasures 
are taken. More than $14 \%$ of people over 60 are not able to live completely independently (WHO, 2020), that is, they are at least partially dependent on support or experience restrictions due to physical limitations. Especially women over 60 are affected by these limitations or need help in everyday situations. This is usually due to a lack of muscle strength (Doherty, 2001; Murtagh and Hubert, 2004). The bodies of those afflicted do not have the ability to function effectively and efficiently, which can also be called poor physical fitness (Corbin and Lindsey, 1997; Corbin et al., 2000). Hence, to prevent the risk of limitations in later life as a woman, it is important to train physical fitness, particularly the component of muscular strength.

Regular physical activity typically engendered through regular physical exercise can promote a high level of physical fitness and greater quality of life for older adults (Suzuki et al., 2002; Tanaka, 2009), even if this activity was started later in adulthood (Rooney, 1993). Evidence shows that a supervised, multicomponent physical exercise program can have positive effects on physical fitness of women of older age (Sousa et al., 2013; Nogueira et al., 2017; De Resende-Neto et al., 2019) by improving muscular strength, balance, and flexibility, which are domains of physical fitness (Corbin et al., 2000).

To achieve a positive effect on muscle strength, and balance with physical exercise programs, a training frequency of 2-3 times per week is recommended (Nakamura et al., 2007; Carneiro et al., 2015; Jungreitmayr et al., 2021; Stojanović et al., 2021). However, improved overall physical fitness tends to show with higher training frequency (Nakamura et al., 2007; Yang et al., 2019). Findings about the impact of training frequency on physical fitness were mostly obtained after supervised training programs where frequency and the duration of the sessions were individually prescribed (Nakamura et al., 2007; Carneiro et al., 2015; Yang et al., 2019; Stojanović et al., 2021).

Although supervised exercise is often considered the superior method to deliver physical exercise (Storer et al., 2014; Fennell et al., 2016), it is not inherently better than unsupervised programs, as those have their own advantages. Unsupervised exercise programs can overcome practical barriers (Schutzer and Graves, 2004) such as transport and cost (Yardley et al., 2006; Davis et al., 2010; Kim et al., 2012) and can be integrated independently into everyday life (Geraedts et al., 2013; Müller et al., 2021). Additionally, there is preliminary evidence suggesting that unsupervised programs delivered using digital technologies (e.g., virtual reality, smartphone, or tablet apps) may have an impact on physical fitness in people of older age. (Van Het Reve et al., 2014; Park and Yim, 2016; Neumann et al., 2018; Yerrakalva et al., 2019; Gao et al., 2020; Van den Helder et al., 2020; Geraedts et al., 2021; Jungreitmayr et al., 2021; Netz et al., 2021). Findings point toward an promising but often not significant (Yerrakalva et al., 2019; Van den Helder et al., 2020; Geraedts et al., 2021), increase in lower body strength, balance, and flexibility, whereas others show significant effects on these markers (Van Het Reve et al., 2014; Park and Yim, 2016; Neumann et al., 2018; Jungreitmayr et al., 2021; Netz et al., 2021). In these studies, measurement of muscle strength, balance, and flexibility was mostly performed via stand-alone tests, such as chair rise (Geraedts et al., 2021; Jungreitmayr et al., 2021; Netz et al., 2021) or uni-pedal stance (Jungreitmayr et al., 2021; Netz et al., 2021), via short physical performance battery (Van Het Reve et al., 2014; Treacy and Hassett, 2018; Van den Helder et al., 2020) or Senior Fitness Test, respectively, (Rikli and Jones, 2013; Neumann et al., 2018).

Remarkably, positive effects on outcomes of these tests have also been demonstrated in studies that used fixed durations of exercise sessions but had the option to self-select training frequency. (Yerrakalva et al., 2019; Geraedts et al., 2021; Jungreitmayr et al., 2021; Mehra et al., 2021; Netz et al., 2021). The above-mentioned evidence suggests that unsupervised training with self-selected training frequency can improve measures of muscular strength, and balance (Geraedts et al., 2021; Jungreitmayr et al., 2021; Netz et al., 2021) and can lead to high adherence rates when it is delivered by modern technologies (i.e., tablets; Van Het Reve et al., 2014; Mehra et al., 2021).

It is important to note that adherence is a complex construct that should not be understood as mere attendance (HawleyHague et al., 2016). In addition to attendance, there are other measures, such as completion of the intervention, adherence to duration, as well as training intensity, that are important to consider good adherence (Hawley-Hague et al., 2016; ColladoMateo et al., 2021). Based on this understanding, Collado-Mateo et al. (2021) identified several key factors that can positively influence adherence, with integration into daily life being one of the most important factors for older adults. Deciding when and where to exercise seems one feasible way to respect personal preferences and achieve high adherence rates. Do older people exercise enough to improve their physical fitness, or is it even more conducive to adherence, and thus outcomes, to further unlock self-selection options, such as the duration of an exercise session?

To the best of our knowledge, it has not yet been investigated whether positive effects on physical fitness and its subdomains can also be achieved, if the participants can self-select their training frequency, and session duration in an unsupervised mode.

Thus, we hypothesize that older women who receive a physical exercise program via a specially designed app, that allows them to determine the duration and frequency of exercise sessions, will exercise sufficiently to achieve significant effects in muscular strength, balance, and flexibility.

\section{MATERIALS AND METHODS}

\section{Study Design}

The study was designed as a randomized controlled trial with a wait-list control group (CG) and has been already extensively reported elsewhere (Trukeschitz et al., 2019). For the field test of the app-based physical exercise program, the control group (CG) was offered the use of the system later (Phase 2, see Figure 1). In addition, after attending all coach appointments and scientific data collection, the CG was prospective to receive a shopping voucher (Trukeschitz et al., 2019).

The app-based physical exercise program thus consisted of a field test with two phases which is presented in Figure 1. 
Phase 1

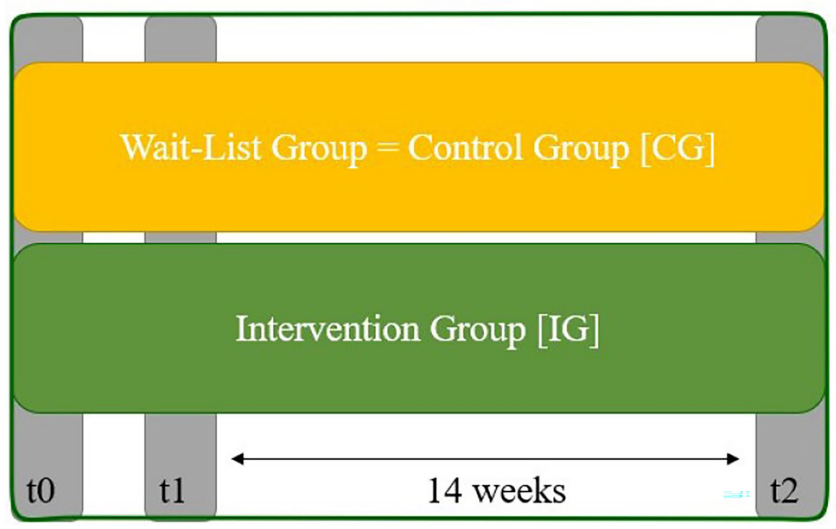

Phase 2

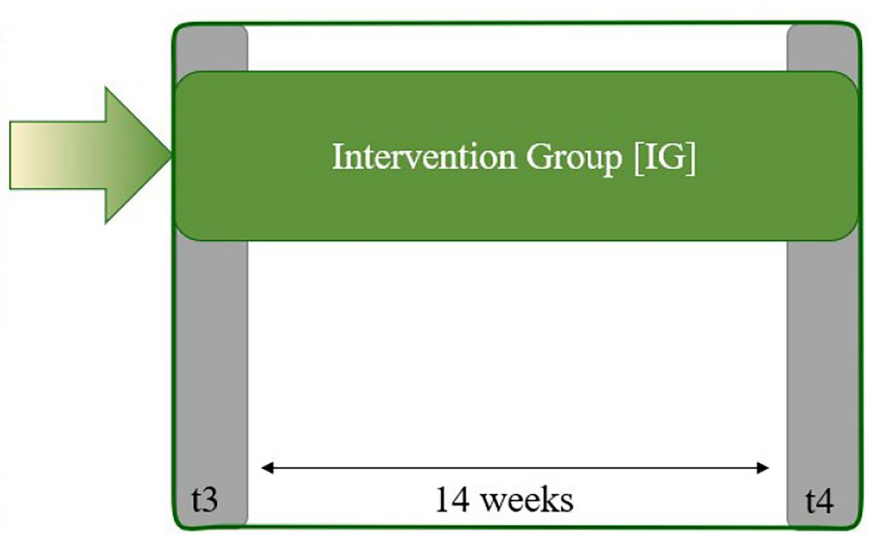

FIGURE 1 | Field test design. Field test design phases; t0, getting to know the coach and assessments; t1, pre-testing for Phase 1, t2, post-testing for phase 1; t3, pre-testing for phase 2 ; 4 , post-testing for phase 2 .

In the first phase, both groups started with the initial assessment appointments with only the test group receiving the app-based program. The waiting group received the system after the end of the first phase and was able to test an improved version of the app in a second phase-which was conducted without a control group. This study examines the results of the first field test phase.

In the first session ( $\mathrm{t} 0$ ), the participants met the coaches and were familiarized with the tests and procedures. The following appointment ( $\mathrm{t} 1$ ), approximately 4 weeks later, was used to conduct the tests and hand out the hardware. After 14 weeks of intervention, the devices were collected, and the final tests were performed ( $\mathrm{t} 2)$.

\section{Participants}

The following criteria were used for the inclusion of the study participants (see Table 1). The criteria were checked during recruitment and served as filters before randomization was performed.

\section{Retirement Age}

The target group consisted of people who had been retired for 2.5-6years. Thus, no explicit age definition was used for recruitment purposes. Instead, effective retirement duration was used as a strict inclusion criterion.

\section{Activity Level}

Individuals were included, who were generally physically active at a maximum of four times per week, that is, subjects who were not engaged in structured exercise training. Those who attended a gym and reported being daily physically active for more than four times per week were excluded, as well as individuals who were already exercising with a personal trainer. This criterion ensured that as many women in retirement as possible were included and that the influence of a concurrent physical exercise program was avoided.
TABLE 1 | Study inclusion criteria.

\begin{tabular}{ll}
\hline Criterion & Measure \\
\hline $\begin{array}{ll}\text { Age } \\
\text { Activity level }\end{array}$ & $\begin{array}{l}\text { No explicit age definition; retired for 2.5-6years. } \\
\text { Physically active individuals (PA up to 4 times per } \\
\text { week); no concurrent physical exercise program }\end{array}$ \\
$\begin{array}{l}\text { Physical condition } \\
\text { Independent, healthy individuals } \\
\text { participation }\end{array}$ & $\begin{array}{l}\text { active desire for exercise and interest in participating } \\
\text { in a scientific study }\end{array}$ \\
Technical requirements & Monitor, 2-2.5 $\mathrm{m}^{2}$ of free space, email address
\end{tabular}

\section{Physical Condition}

Participants were not included when they were dependent on mobility aids such as crutches or wheelchairs. They were also not included if the suffer from any illnesses or physical ailments that could have hindered them from participating in the physical exercise program, such as rheumatism or cardiovascular disease or similar.

\section{Desire for Activity and Participation}

Participants should have had a desire to bring more exercise into their daily lives and were willing to participate in scientific surveys and appointments with the coach.

\section{Technical Criteria}

A tablet was provided to all participants to use the app-based program. A flat screen or monitor was required to use another provisioned technical component of the program, which was a feedback system offered via a depth imaging camera. It was also recommended that approximately $2-2.5 \mathrm{~m}^{2}$ of free space should be available in the home or in front of the monitor when using the depth imaging camera to perform the exercises. In addition, participants were required to have an email address.

\section{Recruiting and Randomization}

As described in Trukeschitz et al. (2019), a three-stage recruitment process before the randomization was performed in order to 
reach the goal of 200-250 study participants. In a first step, letters of invitation were sent out through various channels (e.g., mail, electronic newsletters, magazine and newspaper articles, postings on websites). Those interested were invited to register their wish to participate online or by telephone. A questionnaire developed for this purpose was used to verify the inclusion criteria. The items checked in this questionnaire are listed in "Participants" as well as in Table 1. Registered persons who met all criteria were included as study participants (see Figure 2). Participants were randomly assigned to IG or
CG for the first field test phase and informed consent was obtained from all subjects involved in the study.

\section{Intervention}

The app featured a physical exercise program consisting of functional exercises, a module offering suggestions for outdoor activities (e.g., hiking), e-learning courses dealing with contents on the meaning of fitness and health-enhancing training as well as an overview of the exercise achievements per day.

\section{App-based training for females in retirement age}

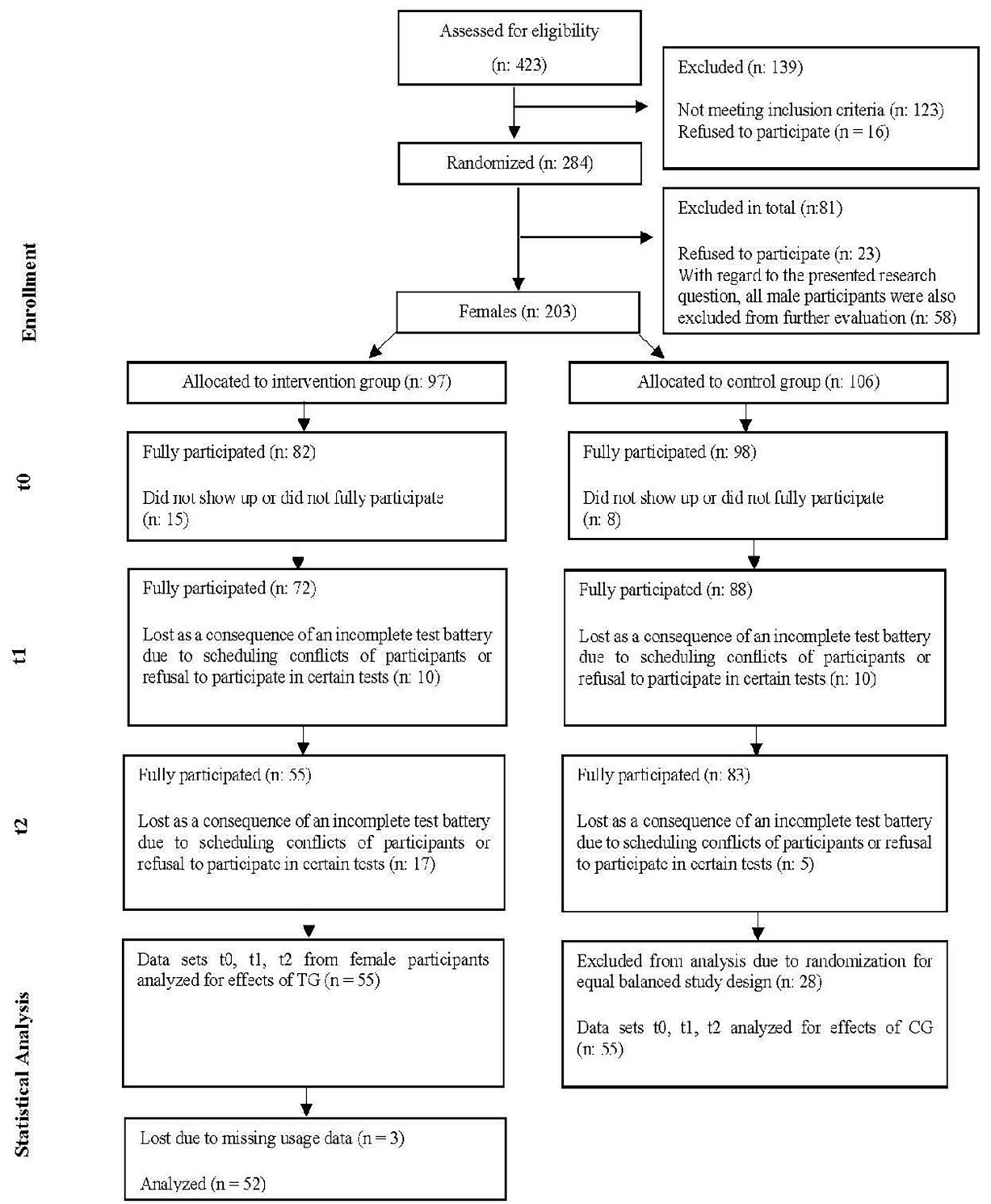

FIGURE 2 | Participant flow. Flow of participants modeled on Boutron et al. (2017). 
For the overall structure of the physical exercise program see Table 2. In the warm-up, cardiovascular stimuli, such as marching in place, were alternated with mobilization exercises, such as shoulder circles or ankle circles, with the duration of exercise set at $40 \mathrm{~s}$.

The main part consisted of resistance and balance exercises. Training volume per resistance exercise was set to two sets as it has been shown to be more efficient when using higher volume compared to single-sets (Kramer et al., 1997; Kraemer and Ratamess, 2004). A set designed to address muscle strength consisted of 8-12 repetitions at a rate of $3 \mathrm{~s}$ per repetition (Cadore et al., 2014; Izquierdo et al., 2021), with exercises that covered the entire range of motion, such as squats, lunges, or table push-ups. The strength part also included exercises with fast but safe movement, such as chair squats, to provide explosive resistance training in addition to the regular strength stimulus (Hazell et al., 2007; Izquierdo et al., 2021). Intensity for strengthening exercises was set to be at RPE 15-18 at BORG Scale, 5-7 at CR-10 scale, respectively (Williams, 2017; Izquierdo et al., 2021). Rests between sets were planned to be around 1-3 min (Izquierdo et al., 2021) and automatically generated via structure of the session as the exercises were organized in mini-circuits (see Table 2). Balance exercises, such as variations of uni-pedal or tandem stands were set at 40s per set (Lesinski et al., 2015). In the cooldown phase, static stretching was applied for a volume of two sets at $40 \mathrm{~s}$ per set (Page, 2012). Accordingly, the training sessions were designed in such a way that performing the shortest session twice a week satisfied the minimum requirements in terms of muscular strength and coordination training (Garber et al., 2011; Izquierdo et al., 2021).

More detailed information about the exercise program is shown in Table 2 (i.e., overview on the structure of an exercise session) and Table 3 (i.e., overview on exercise and training variables). The aim was to create a load profile that was as homogeneous as possible while also considering individual performance (Herold et al., 2020).

The exercise program could be accessed and viewed directly in the app on the tablet, but also used in conjunction with an exercise feedback system (Orbecc Persee) on the TV or monitor, which gave direct feedback on the correct execution of the movements (Venek et al., 2021).

The intervention started with two appointments with the coach. The first appointment (t0, see Figure 1) served to getting

TABLE 2 | Structure of training sessions.

\begin{tabular}{|c|c|c|c|}
\hline Structure & 10-min session & 20-min session & 30-min session \\
\hline Warm-up & $\begin{array}{l}2 \text { sets of } 3 \text { exercises [exercises for the } \\
\text { cardiovascular system and mobilization of } \\
\text { joints] } \\
\text { e.g., marching in place for } 40^{\prime \prime} \\
\text { shoulder circles for } 40^{\prime \prime} \text { leg swings for } 40^{\prime \prime} \\
\text { repeat all three exercises }\end{array}$ & $\begin{array}{l}2 \text { sets of } 4 \text { exercises [exercises for the } \\
\text { cardiovascular system and mobilization of joints] } \\
\text { e.g., marching in place for } 40^{\prime \prime} \\
\text { shoulder circles for } 40^{\prime \prime} \\
\text { leg swings for } 40^{\prime \prime} \\
\text { ankle circles for } 40^{\prime \prime} \text { repeat all four exercises }\end{array}$ & $\begin{array}{l}2 \text { sets of } 5 \text { exercises [exercises for the cardiovascular } \\
\text { system and mobilization of joints] } \\
\text { e.g., marching in place for } 40^{\prime \prime} \\
\text { shoulder circles for } 40^{\prime \prime} \\
\text { leg swings for } 40^{\prime \prime} \\
\text { ankle circles for } 40^{\prime \prime} \\
\text { high knee march and arm swings for } 40^{\prime \prime} \\
\text { repeat all five exercises }\end{array}$ \\
\hline Main part & $\begin{array}{l}2 \text { sets of } 3 \text { exercises } \\
{[1 / 3 \text { balance and } 2 / 3 \text { strength exercises] }} \\
\text { e.g., uni-pedal stance for } 40^{\prime \prime} \\
\text { chair squats for } 8-12 \text { reps } \\
\text { table push-ups for } 8-12 \text { reps repeat all } \\
\text { three exercises }\end{array}$ & $\begin{array}{l}2 \text { sets of } 6 \text { exercises } \\
\text { [1/3 balance and } 2 / 3 \text { strength exercises] } \\
\text { e.g., uni-pedal stance for } 40^{\prime \prime} \\
\text { chair squats for } 8-12 \text { reps } \\
\text { table push-ups for } 8-12 \text { reps repeat all three } \\
\text { exercises } \\
\text { tandem stance for } 40^{\prime \prime} \\
\text { lunges for } 8-12 \text { reps } \\
\text { upright row with elastic band for } 8-12 \text { reps } \\
\text { repeat all three exercises }\end{array}$ & $\begin{array}{l}2 \text { sets of } 10 \text { exercises } \\
\text { [1/3 balance and } 2 / 3 \text { strength exercises] } \\
\text { e.g., uni-pedal stance for } 40^{\prime \prime} \\
\text { chair squats for } 8-12 \text { reps } \\
\text { table push-ups for } 8-12 \text { reps repeat all three } \\
\text { exercises } \\
\text { tandem stance for } 40^{\prime \prime} \\
\text { lunges for } 8-12 \text { reps } \\
\text { bent over row with elastic band for } 8-12 \text { reps } \\
\text { crunch for } 8-12 \text { reps } \\
\text { repeat all four exercises } \\
\text { front scale variation for } 40^{\prime \prime} \\
\text { unilateral calf raises for } 8-12 \text { reps } \\
\text { planks for } 40^{\prime \prime} \text { repeat all three exercises }\end{array}$ \\
\hline \multirow[t]{3}{*}{ Cooldown } & $\begin{array}{l}2 \text { sets of } 2 \text { exercises [stretching exercises } \\
\text { for upper and lower body] }\end{array}$ & $\begin{array}{l}2 \text { sets of } 3 \text { exercises [stretching exercises for } \\
\text { upper and lower body] }\end{array}$ & $\begin{array}{l}2 \text { sets of } 4 \text { exercises [stretching exercises for upper } \\
\text { and lower body] }\end{array}$ \\
\hline & $\begin{array}{l}\text { e.g., hip flexor stretch for } 40^{\prime \prime} \\
\text { triceps stretch for } 40^{\prime \prime} \\
\text { repeat both exercises }\end{array}$ & $\begin{array}{l}\text { e.g., hip flexor stretch for } 40^{\prime \prime} \\
\text { triceps stretch for } 40^{\prime \prime} \\
\text { calf stretch for } 40^{\prime \prime} \text { repeat all three exercises }\end{array}$ & $\begin{array}{l}\text { e.g., hip flexor stretch for } 40^{\prime \prime} \\
\text { triceps stretch for } 40^{\prime \prime} \\
\text { calf stretch for } 40^{\prime \prime}\end{array}$ \\
\hline & & & neck stretch for $40^{\prime \prime}$ repeat all four exercises \\
\hline
\end{tabular}


TABLE 3 | Load prescription

\begin{tabular}{|c|c|c|}
\hline $\begin{array}{l}\text { Exercise/Training } \\
\text { variables }\end{array}$ & Specification & Defaults \\
\hline Type of exercise & Predefined & Given via structure (see Table 1) \\
\hline Exercise duration & Predefined & $8-12$ repetitions OR 40s \\
\hline Exercise intensity & Recommended & RPE 5-7/vigorous intensity \\
\hline Training frequency & Recommended & 2-3 times per week \\
\hline Training density & Self-selected & From daily to no usage \\
\hline $\begin{array}{l}\text { Duration of a single } \\
\text { exercise session }\end{array}$ & Self-selected & 10,20, or $30 \mathrm{~min}$ \\
\hline
\end{tabular}

to know the coach, and trial procedures. The testing was explained, and familiarization tests were conducted to rule out potential learning effects. Furthermore, the concept of ratings of perceived exertion (RPE; Kilpatrick et al., 2020) was introduced so that the participants could learn to use it to assess intensities. More specifically, the CR-10 scale was used as the session RPE (Day et al., 2004; Arney et al., 2019), which allows effort to be rated in conjunction with the total load of the entire training session. Coaches anchored the scale by asking participants to recall training experiences that would provide a reference point for how the range of training intensity felt (Kilpatrick et al., 2020) The participants were instructed to perform all muscular strength exercises in vigorous (hard) intensity, using provided aids such as a ball and the elastic band as increase in strain where necessary (Colado et al., 2010; Martins et al., 2013).

After the second coach appointment (t1, see Figure 1), the coach assigned the participants of the IG to an individual difficulty level. Apart from this action, there were no differences in the treatment between the participants of the IG and CG for the course of the appointment. Another person handed out the equipment to the IG, provided information on the setup and technical use of the system. After this appointment, where they were reminded to exercise at vigorous intensities and advised to exercise at least 2-3 times per week, participants were free to decide when and where they wanted to use the system during the following 14 weeks. In addition to these choices, they could also decide for each session whether they wanted to do a 10-, 20-, or 30-min workout designed according to the latest recommendations for exercise for older people, as shown in Table 2 (Zaleski et al., 2016; Fragala et al., 2019).

In the last appointment with the coach ( 2 , see Figure 1), the post-testing was carried out. The participants of the IG were able to return the devices independently, so that the final appointments could be designed the same for both groups.

The study was positively evaluated by the ethics committee of the University of Salzburg (EK-GZ: 09/2018).

\section{OUTCOMES AND TEST PROCEDURES}

All test procedures were conducted before and after the intervention (see Figure 1).

\section{Lower Body Strength via 30CR}

Sit-to-stand test are simple but good means to evaluate lower body strength (Csuka and McCarty, 1985; Guralnik et al., 1994; Bennell et al., 2011; Rikli and Jones, 2013). The 30-S ChairRise Test (30CR) is valid and reliable measure to evaluate lower body strength in community-dwelling adults of age (Jones et al., 1999; Rikli and Jones, 2013). The aim of this test was to complete as many stand-ups and sit-downs as possible within $30 \mathrm{~s}$. The starting position was sitting on a standardized chair $(\sim 43 \mathrm{~cm})$. The arms were held crossed at chest height. Feet were placed in hip-to-shoulder with stance. The stand-up procedure was completed when the hip and knee joints were fully extended. The sit-down procedure was completed when the buttocks fully touched the seat surface. On the command "ready, go!" this process had to be repeated as often as possible. The actions were counted to the nearest half, that is, if only standing up was completed in the last attempt, half a point was awarded for this.

\section{Balance via UPS}

The ability to maintain static balance was evaluated by the uni-pedal stance test (Springer et al., 2007). The test person was asked to stand quietly on one leg for as long as possible without touching the slightly bent standing leg with the playing leg. Arms on her hips, the person had to fixate on a point on a wall at eye level. On the command of "ready, go!" the participant had to lift off one leg. Testing was performed on both sides alternately for three trials each. Times were measured with stopwatches to the nearest tenth of a second. The best of three trials was used for further analysis (Granacher et al., 2014).

\section{Isometric Handgrip Strength (GRIP) via Handheld Dynamometer}

Handgrip strength has been established as an inexpensive surrogate marker for overall muscular strength (Duchowny et al., 2017; Bohannon, 2019). It was measured using a hand dynamometer (Jamar-hydraulic hand dynamometer, Sammons Preston, United States). As recommended by The American Society of Hand Therapists (Fess, 1992), the participant sits on an armchair without using the backrest and lets the hand not to be tested hang down loosely while the side to be tested is bent $90^{\circ}$ at the elbow, with the neutral hand position facing forward. Before the measurement, the person is told that the force should be built up smoothly. On the command "ready, go," the participant should squeeze as hard as possible. Three trials were performed for each hand while after one trial the hand was changed. The arithmetic mean of all trials was evaluated. The measurement results in values in $\mathrm{kg}$ (Innes, 1999; Wang et al., 2018).

\section{Isometric Muscular Strength Testing via Digital Handheld Dynamometer}

Testing maximal isometric voluntary contraction with handheld dynamometry is a reliable method of testing strength of different muscle groups (Mentiplay et al., 2015; Buckinx et al., 2017) 
and was performed in standardized positions, all chosen so that stronger individuals could exert full force without the muscular strength of the person testing being the limiting factor (Krause et al., 2014). The test person held a mobile hand dynamometer (MicroFET2, Hoggan Scientific LLC, United States) against the measuring point of the person to be tested. The subjects were told not to apply the force in a sudden burst, but to build it up continuously within 1-2s. The person to be tested had to start at the command "ready, go" and counteract insurmountable resistance in the position for about $4 \mathrm{~s}$ (Kolber and Cleland, 2005; Zander, 2018). All tests were performed on both sides alternately for three trials each. The arithmetic mean of all trials per test was evaluated. Results were recorded in kilopond. The following assessments were conducted:

\section{Seated Shoulder Abduction (ShoulderF)}

Shoulder abduction was measured in a seated position with the subject sitting upright on a chair without using the backrest. The arm under test had to be raised to shoulder level with $90^{\circ}$ flexion at the elbow joint and upward pressure had to be applied against the dynamometer placed at the distal end of the upper arm.

\section{Lying Hip Extension (HipExtF)}

The extension of the hip was tested in prone position. The person to be tested lay on a padded table and used his hands as a pillow to avoid using her arms. The hand dynamometer was placed on the back of the thigh just after the back of the knee.

\section{Side Lying Hip Abduction (HipAbdF)}

Abduction in the hip joint was tested in the lateral position. The person to be tested lay on a padded table with the lower leg bent and both hands as head cushions and held the leg to be tested at hip level (Wieben and Falkenberg, 2001; Hislop et al., 2013). The hand dynamometer was placed directly above the outer ankle at the distal end of the leg.

\section{Arm Flexion (BicF)}

Arm flexion was measured in the supine position on a padded table. Subjects held their hand in a supinated position, elbow angle at $90^{\circ}$, and had to apply resistance against the device being held at the distal end of the forearm, while the untested arm had to rest beside the body.

\section{Flexibility via Range of Motion Testing Lower Body (LegMob)}

Straight-Leg-Raise Tests are a common measure to evaluate hamstring flexibility (Göeken and Hof, 1994; Halbertsma et al., 2001; Marshall et al., 2011; Ayala et al., 2012). In order to reliably evaluate the Straight-Leg-Raise Test, it was performed using a digital inclinometer (Van Blommestein et al., 2012).

The subjects lay supine on a padded table. The coach fixed the leg not to be tested and gently lifted the leg to be tested until the subject gave the stop signal. In this position, the angle of the leg to the lying surface was measured using an inclinometer and noted to the nearest one degree. Both legs were measured in this way.

\section{Upper Body (ShoulderMob)}

This test assessing shoulder flexion was performed in the supine position on a padded bench. The extended arm of the test person was brought above the head, while care was taken to ensure that the thorax remained in contact with the bench so that the amplitude of movement in the shoulder joint could actually be measured (Bartrow, 2012).

\section{Exercise Adherence}

Exercise adherence can be described by four measures: Completion of the intervention, adherence to duration, and training intensity (Hawley-Hague et al., 2016), whereas attendance serves as singular proxy for adherence in many studies (Geraedts et al., 2014; Van Het Reve et al., 2014; Hawley-Hague et al., 2016; Van den Helder et al., 2020; Jungreitmayr et al., 2021; Mehra et al., 2021). We used frequency and duration of the app usage to operationalize adherence to the exercise program. These data were collected by using a logging software (Matomo, InnoCraft, 150 Willis St, Wellington, New Zealand) which automatically recorded usage data. The following usage features were of interest for the analysis:

\section{Usage Frequency (Visit)}

Frequency of usage served as a proxy for attendance. Each use of the app-based physical exercise program was defined as a visit to the app. A visit was defined as the mean usage of the app on the tablet or on the feedback system, whereby all interactions were recorded as one visit, if there were no breaks longer than $30 \mathrm{~min}$. For example, if the feedback system was turned on and off multiple times within $30 \mathrm{~min}$, this counted as a visit. However, if the app was used on the tablet once in the morning and again in the afternoon, this counted as two independent visits. To be able to exclude visits without actual activity, only those visits were analyzed that consisted of at least two actions. For example, if a participant opened the app on the tablet and then selected the training program this was counted as a visit. Just opening the app alone did not count as a visit.

\section{Training Duration (TrgDur)}

The training duration originates from the database created by the logging component. It describes the total time during the intervention phase in which the exercise program of the app was used.

\section{Number of Workouts (Workouts_nr)}

The workout data came from the logged data and a workout was counted as completed when the summary screen was displayed. However, it did not matter if all or only some exercises from the workout were completed. If no exercises were completed, no result was sent to the server-which means that these attempts were not counted. 


\section{Percentage Distribution of the Different Workout Durations (\%10 Min; \%20Min; \%30Min)}

As with the number of workouts, the percentage of workouts completed was taken from the logged data. For example, if the last screen of a 10-min workout was displayed and at least one of the exercises was considered completed, the workout was considered completed. In this way, all 10-, 20-, and 30-min workouts were counted. The percentage was then calculated by dividing the number of each workout group by the total number of workouts and then multiplied by 100 .

\section{Statistical Methods}

Statistical analysis was carried out using SPSS (version 27.0; IBM Corp., Armonk, NY, United States). Baseline data were described with mean \pm standard deviation. To evaluate if there were any group differences at baseline, we calculated an independent samples Welch's t-test and took Cohen's $d$ as the effect size. As proposed in Cohen (1988) we use the following limits to interpret effect size: 0.2 small effect, 0.5 moderate effect, 0.8 large effect.

Normal distribution of data was checked by Shapiro-Wilk's test. As all data were distributed accordingly and did not violate Levene's test for equality of variances, repeated measures analysis of covariances (ANCOVAs) adjusted to corresponding baseline scores were conducted to assess changes between groups over time for each fitness outcome. The level of significance was set to $p<0.05$. Adjusted values of $p$ are presented. Effect sizes are expressed as $\eta_{p}^{2}$, whereas the effect is considered to be a small effect at 0.01 , moderate at 0.06 , and large at 0.14 (Cohen, 1988).

To find out whether different use of the system had an impact on the effects, the TG was divided into subgroups, and their usage behavior was analyzed descriptively. Visits were used to separate the participants into subgroups based on how often they used the system. Group intervals were defined with the Jenks natural breaks algorithm (Jenks, 1967). Thus, participants were grouped into four groups based on usage frequency, from non-users to frequent users. Frequent users used the training program 4.1-11.6 times per week $(n=13)$, occasional users $2.4-4.0$ times per week $(n=9)$ rare users $1.2-2.4$ times per week $(n=15)$ and non-users were logged to use below 1.2 times per week $(n=15)$.

Differences in exercise load characteristics between groups were assessed via ANOVA. Again, the level of significance was set to $p<0.05$. Adjusted values of pare presented. Effect sizes are expressed as $\eta_{p}^{2}$ as described before (Cohen, 1988). If significant differences between subgroups were found, pairwise comparisons were performed using the Scheffé (1970) procedure.

Finally, another ANCOVA procedure was run to evaluate if fitness outcomes that significantly differed between IG and CG in general also differed between subgroups of the TG. Again the same procedure was used for the description of significance and effect sizes expressed as $\eta_{p}^{2}$ (Cohen, 1988).

\section{RESULTS}

\section{Participant Flow}

After a first recruitment phase in which a total of 423 persons could be reached, 284 persons were included after applying the exclusion criteria and randomly assigned to the test or control group (see Figure 2). As 23 individuals canceled after randomization, 261 participants remained, of whom 203 were women who were thus included in this analysis. Over the course of the field test, participants were always excluded from the statistical analysis if they did not show up or showed up too late for a test appointment or did not want to complete the test battery for some other reason. It should be noted that during the study, there were no discontinuations due to injuries from using the system or the like. Furthermore, no adverse side effects were reported. For the statistical evaluation, 55 data sets of the TG were available at the end of the first field test phase (see Figure 1). To obtain a balanced evaluation design, 55 data sets were randomly drawn from the 83 data sets of the CG. For the detailed evaluation of the subgroups of the TG, another 3 missing had to be accepted, since usage data were missing here. Therefore, these evaluations were carried out with 52 instead of 55 data sets.

\section{Baseline Data}

Table 4 shows that with a mean of $16.6( \pm 3.3)$ and $15.7( \pm 4.7)$ chair-rise repetitions in IG and CG respectively, the participants scored well above the norm values for women within the age group of $60-64$ years $(14.5 \pm 4.0)$ as well as for those within $65-69$ years of age $(13.5 \pm 3.5)$ indicating a very good physical fitness regarding lower body strength (Rikli and Jones, 1999). Overall muscular strength represented via handgrip strength (IG: $26.5 \pm 4.8$; CG $26.5 \pm 4.9$ ) also showed above average fitness regarding this parameter compared to norm values for both

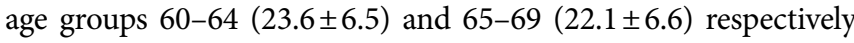
(Wang et al., 2018). Balance assessed via Uni-Pedal Stance (UPS) showed a highly above ability compared to the norm values of women between 60 to 69 years of age with 30.4 ( \pm 16.4 ), being $50.8( \pm 18.0)$ in IG and $52.3( \pm 17.5)$ in CG (Springer et al., 2007). Range of motion tests showed good flexibility in both shoulder and hip joint, whereby the maximum limits of $180^{\circ}$ in the shoulder joint and $140^{\circ}$ in the hip joint (Bartrow, 2012)

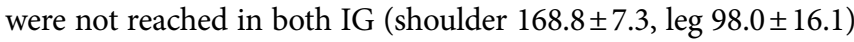
and CG (shoulder 171.4 \pm 6.7 ; leg $99.7 \pm 16.9$ ) at baseline.

Baseline data (see Table 4) showed a statistically significant difference with moderate effect size between groups in isometric muscular strength when flexing the elbow joint, but in no other outcome criteria. To account for baseline differences further calculations regarding effects over time between groups were adjusted to baseline ( $\mathrm{t} 1$ ) values.

\section{Outcomes and Estimation}

The findings show positive results on the physical fitness of the IG compared to the TG. Univariate repeated measures analyses of covariances show statistically significant differences between groups in isometric strength at hip extension, hip 
TABLE 4 | Baseline data of test and control group.

\begin{tabular}{|c|c|c|c|c|c|c|c|c|c|c|}
\hline \multirow{2}{*}{ Baseline data } & \multicolumn{2}{|c|}{ IG (n: 55) } & \multicolumn{2}{|c|}{ CG (n: 55) } & \multicolumn{4}{|c|}{ Welch's $t$-test } & \multicolumn{2}{|c|}{$95 \% \mathrm{Cl}$ of the differences } \\
\hline & $M$ & SD & $M$ & SD & $t$ & df & $p$ & Cohen's $d$ & Lower & Upper \\
\hline Age, yrs & 65.4 & 1.5 & 65.2 & 1.5 & 0.698 & 107.804 & 0.487 & 1.503 & -0.368 & 0.768 \\
\hline t1_30CR, cts & 16.6 & 3.3 & 15.7 & 4.7 & 1.285 & 97.612 & 0.202 & 0.245 & -0.5 & 2.5 \\
\hline t1_UPS, s & 50.8 & 18.0 & 52.3 & 17.5 & -0.449 & 107.913 & 0.655 & 0.086 & -8.2 & 5.2 \\
\hline t1_Grip, kg & 26.5 & 4.8 & 26.5 & 4.9 & -0.045 & 107.981 & 0.964 & 0.009 & -1.9 & 1.8 \\
\hline t1_ShoulderF, kg & 11.6 & 2.7 & 11.2 & 2.0 & 0.900 & 99.664 & 0.370 & 0.172 & -0.5 & 1.3 \\
\hline t1_HipExtF, kg & 15.0 & 3.0 & 15.6 & 4.1 & -0.949 & 98.546 & 0.345 & 0.181 & -2.0 & 0.7 \\
\hline t1_HipAbdF, kg & 10.8 & 2.4 & 10.5 & 2.5 & 0.584 & 107.764 & 0.560 & 0.111 & -0.6 & 1.2 \\
\hline t1_BicF, kg & 14.9 & 2.5 & 16.1 & 3.1 & -2.261 & 104.072 & 0.026 & 0.431 & -2.3 & -0.1 \\
\hline t1_ShoulderMob & 168.8 & 7.3 & 171.4 & 6.7 & -1.905 & 107.175 & 0.059 & 0.363 & -5.2 & 0.1 \\
\hline t1_LegMob & 98.0 & 16.1 & 99.7 & 16.9 & -0.527 & 107.721 & 0.600 & 0.100 & -7.9 & 4.6 \\
\hline
\end{tabular}

t1, baseline test date; 30CR, 30-s Chair-Rise Test expressed in counts (cts); UPS, Uni-Pedal Stance Test expressed in seconds (s); Grip, Handgrip Strength Test expressed in kilogram (kg) - as are all isometric strength measurements; ShoulderF, isometric strength testing for shoulder abduction; HipExtF, isometric strength testing for prone hip extension; HipAbdF, isometric strength testing for side lying hip abduction; BicF, isometric strength testing for elbow flexion; ShoulderMob, range of motion testing for shoulder flexion expressed in degrees; LegMob, range of motion testing for hip flexion in lying supine position expressed in degrees.

abduction, elbow flexion, and in both parameters regarding range of motion testing. The analyses showed moderate effect sizes on all results, except for the difference in elbow flexion isometric force, which indicated a large effect (see Table 5).

The descriptive analysis of subgroups considering usage of the program provides an overview regarding exercise adherence markers (see Table 6). Pairwise comparisons showed a significant difference in number of workouts between all groups and a significant difference in training duration between all groups, except between occasional and rare users with a $p=0.381$, 95\% CI $[-2.1 ;-11.2]$.

To assess if usage frequency led to different results, univariate ANOVAs were calculated for the subgroups, as can be seen in Table 7.

Subgroup analysis showed that despite presenting significantly different duration of training, number of workouts (see Table 6) there were no significant differences between the usage-based subgroups of the TG (see Table 7).

\section{DISCUSSION}

With our study, we investigated the effects on an app-based physical exercise program on physical fitness. Our main findings imply that participants who used the app-based physical exercise program had significantly positive effects on muscle strength and flexibility compared to the control group.

Our sample consisted of women over 60 years of age who, compared with their peers, could be considered fit. As our data show, the adherence rate (in terms of attendance) was $71 \%$, which means 37 of 52 participants used the exercise program at least 1.2-2.4 times per week. This adherence rate exceeds general web-based interventions, which have on average $50 \%$ and once-weekly use (Kelders et al., 2012), as well as typically reported rates for exercise programs, often with half of participants quitting (Chao et al., 2000; Picorelli et al., 2014). The use of new technology in the current study (i.e., tablets) might have led to the relatively high adherence rates in our study which is in line with observations of previous studies utilizing modern technologies to deliver physical exercise programs (Valenzuela et al., 2018; Mehra et al., 2021). Additionally, the autonomy to freely chose the duration of a single exercise session and training frequency which can allow for a better integration of physical exercises into everyday life, could be another reason for the good adherence (Collado-Mateo et al., 2021) as we were able to achieve slightly better adherence rates than in programs where session duration was fixed, which achieved adherence rates of 60-69\% among completers (Geraedts et al., 2014; Jungreitmayr et al., 2021; Mehra et al., 2021).

Our results invite a nuanced consideration of the effects of an app-based physical exercise program for women aged 60 years and older, as functional performance of lower body strength, handgrip strength, and balance remained unchanged, whereas muscular strength and range of motion tests showed significant improvements in IG compared with CG. At first glance, these results are unexpected, as the exercise program was aligned with current recommendations (Garber et al., 2011; Cadore et al., 2014; Fragala et al., 2019; Izquierdo et al., 2021) and contained all the necessary stimuli, such as training in repetition ranges from 8 to 12 , fast movements and recommended training intensities from moderate to demanding, all which were found to produce positive effects on physical fitness, as well as its components, in older adults (Bemben et al., 2000; Hunter et al., 2001; Kalapotharakos et al., 2005; Richardson et al., 2019; Herda et al., 2020). Furthermore, the usage data also show that the exercise frequency was well within in a range that should be able to produce effects, since even one or two sessions per week have been proven able to do this (Taaffe et al., 1999; Richardson et al., 2019; Jungreitmayr et al., 2021; Stojanović et al., 2021). While neither the frequency of use nor the composition of the program can be considered a reason for the lack of effect on lower body strength and handgrip strength, the testing procedure itself as well as the uncertainty whether the participants have reached the appropriate exercise intensity (due to the unsupervised mode of the exercise program) remain possible reasons for these results. It should 
TABLE 5 | Effects over time between test and control group.

\begin{tabular}{|c|c|c|c|c|c|c|c|c|}
\hline & \multirow[b]{2}{*}{ IG/n: $55 \Delta M$} & \multirow[b]{2}{*}{ CG/n: $55 \Delta M$} & \multirow[b]{2}{*}{ SE } & \multicolumn{3}{|c|}{ ANCOVA } & \multicolumn{2}{|c|}{$95 \% \mathrm{Cl}$ of the differences } \\
\hline & & & & $p$ & $F(1,107)$ & $\eta_{p}^{2}$ & Lower & Upper \\
\hline $30 \mathrm{CR}$, cts & 0.118 & 0.673 & 0.312 & 0.213 & 1.573 & 0.014 & -0.716 & 0.161 \\
\hline UPS, sec & 1.827 & 1.839 & 0.993 & 0.933 & 0.000 & 0.000 & -1.398 & 1.386 \\
\hline Grip, kg & 0.875 & 1.403 & 0.329 & 0.259 & 1.289 & 0.012 & -0.725 & 0.197 \\
\hline ShoulderF, kg & 0.214 & -0.504 & 0.301 & 0.095 & 2.832 & 0.026 & -0.064 & 0.783 \\
\hline HipExtF, kg & -0.007 & -2.19 & 0.491 & 0.002 & 9.833 & 0.084 & 0.402 & 1.782 \\
\hline HipAbdF, kg & 0.292 & -0.692 & 0.257 & 0.008 & 7.332 & 0.064 & 0.132 & 0.853 \\
\hline BicF, kg & 0.641 & -1.798 & 0.365 & 0.001 & 21.827 & 0.169 & 0.702 & 1.737 \\
\hline ShoulderMob & 2.601 & 0.407 & 0.661 & 0.022 & 5.421 & 0.048 & 0.163 & 2.032 \\
\hline LegMob & 7.269 & 0.870 & 1.260 & 0.001 & 12.875 & 0.107 & 1.432 & 4.967 \\
\hline
\end{tabular}

Repeated measures analysis of covariance adjusted to baseline; $\Delta$, mean difference t2-t1 within group; 30CR, 30-s Chair-Rise Test expressed in counts (cts); UPS, Uni-Pedal Stance Test expressed in seconds (s); Grip, Handgrip Strength Test expressed in kilogram (kg) - as are all isometric strength measurements; ShoulderF, isometric strength testing for shoulder abduction; HipExtF, isometric strength testing for prone hip extension; HipAbdF, isometric strength testing for side lying hip abduction; BicF, isometric strength testing for elbow flexion; ShoulderMob, range of motion testing for shoulder flexion expressed in degrees; LegMob, range of motion testing for hip flexion in lying supine position expressed in degrees.

TABLE 6 | Descriptive analysis of subgroups considering usage of the exercise program.

\begin{tabular}{|c|c|c|c|c|c|c|c|c|c|c|c|}
\hline & \multicolumn{2}{|c|}{ Frequent users/n: 13} & \multicolumn{2}{|c|}{ Occasional users/n: 9} & \multicolumn{2}{|c|}{ Rare users/n: 15} & \multicolumn{2}{|c|}{ Non-users/n: 15} & \multicolumn{3}{|c|}{ ANOVA } \\
\hline & $M$ & $S D$ & $M$ & $S D$ & $M$ & $S D$ & $M$ & $S D$ & $p$ & $F(3 / 48)$ & $\eta_{p}^{2}$ \\
\hline Age, yrs & 65.0 & 1.6 & 65.1 & 1.3 & 65.8 & 1.7 & 65.9 & 1.8 & 0.354 & 1.110 & 0.065 \\
\hline Trg. Dur, h & 24.7 & 8.3 & 15.0 & 7.0 & 10.4 & 4.5 & 3.2 & 2.3 & 0.001 & 32.991 & 0.673 \\
\hline Workouts, $\mathrm{n}$ & 65.3 & 18.7 & 41.3 & 15.3 & 23.5 & 6.7 & 8.8 & 5.7 & 0.001 & 54.342 & 0.773 \\
\hline$\% 30$ min & 21.8 & 25.2 & 24.3 & 27.2 & 32.5 & 36.1 & 16.9 & 31.5 & 0.579 & 0.662 & 0.040 \\
\hline
\end{tabular}

Frequent users used the physical exercise program 4.1-11.6 times per week; occasional users 2.4-4.0 times per week; rare users 1.2-2.4 times per week; non-users: below 1.2 times per week; Trg. Dur, total duration of training within the intervention period expressed in hours; Workouts, total number ( $n$ ) of workouts completed within the intervention period; $\% 10$ min, percentage of 10-min training sessions over the entire intervention period; \%20 min and \%30 min, corresponding to the same measure as for \% 10 min.

TABLE 7 | Effects over time between subgroups.

\begin{tabular}{|c|c|c|c|c|c|c|c|c|c|c|c|}
\hline & \multicolumn{2}{|c|}{ Frequent users/n: 13} & \multicolumn{2}{|c|}{ Occasional users/n: 9} & \multicolumn{2}{|c|}{ Rare users/n: 15} & \multicolumn{2}{|c|}{ Non-users/n: 15} & \multicolumn{3}{|c|}{ ANOVA } \\
\hline & $M$ & $S D$ & $M$ & $S D$ & $M$ & $S D$ & $M$ & $S D$ & $p$ & $F(3 / 48)$ & $\eta_{p}^{2}$ \\
\hline$\Delta \_$HipExtF, kg & -0.469 & 3.922 & 0.633 & 3.420 & 1.527 & 3.131 & -0.733 & 2.641 & 0.236 & 1.464 & 0.084 \\
\hline$\Delta \_H i p A b d F, k g$ & 0.239 & 1.239 & 0.478 & 1.506 & 0.773 & 1.123 & 0.047 & 1.241 & 0.441 & 0.915 & 0.054 \\
\hline$\Delta \_$BicF, kg & 0.646 & 2.642 & 0.611 & 2.418 & 1.213 & 2.020 & 0.733 & 3.021 & 0.921 & 0.163 & 0.010 \\
\hline$\Delta$ _ShoulderMob & 3.792 & 3.867 & 1.150 & 3.034 & 2.120 & 4.399 & 3.857 & 4.789 & 0.339 & 1.150 & 0.067 \\
\hline$\Delta \_$LegMob & 8.439 & 11.028 & 6.033 & 7.198 & 6.610 & 7.847 & 6.643 & 9.933 & 0.922 & 0.162 & 0.010 \\
\hline
\end{tabular}

Frequent users used the physical exercise program 4.1-11.6 times per week; occasional users 2.4-4.0 times per week; rare users 1.2-2.4 times per week; non-users: below 1.2 times per week; univariate analysis of variance using $\Delta$ (t2-t1); HipExtF, isometric strength testing for prone hip extension; HipAbdF, isometric strength testing for side lying hip abduction; BicF, isometric strength testing for elbow flexion; ShoulderMob, range of motion testing for shoulder flexion expressed in degrees; LegMob, range of motion testing for hip flexion in lying supine position expressed in degrees.

be considered that the participants in the 30-s Chair-Rise Test have already started with a very good result and the test, although it could show good discrimination between highly active and low active individuals (Jones et al., 1999), may not discriminate sufficiently within this active population, which means that a significant improvement of the already high level may not be noticed using this test.
Furthermore, a lack of an appropriate intensity remains a possible explanation. Even though many different intensities can be used successfully (Bemben et al., 2000; Hunter et al., 2001; Kalapotharakos et al., 2005), an actual moderate to high exercise intensity, achieved via the repetition velocity of an exercise, seems to be advisable in order to achieve an improvement in the chair standing tests (Alexander et al., 2001). Although 
exercise intensity was prescribed via rating of perceived exertion, it was up to the participants to actually achieve this intensity and there is a possibility that exercises were done at other intensities (Kilpatrick et al., 2020). Evidence exists that selfselected exercise intensity is often below the recommended one (Focht, 2007; Elsangedy et al., 2013; Dias et al., 2018). Notably, recent studies dealing with unsupervised technologybased programs have faced similar challenges, with chair-rise tests producing promising but not significant results (Yerrakalva et al., 2019; Van den Helder et al., 2020; Geraedts et al., 2021). Hence, we conclude that self-selected exercise intensity of a home-based training causes lower effects compared to a supervised training (Thiebaud et al., 2014; Lacroix et al., 2017). This holds especially true when studying the effects on physical fitness in healthy participants by means of chair-rise test (Lacroix et al., 2017).

Regarding balance ability, it must be noted that this was already set at such a high level compared to age-specific norm values at the start of the intervention that no further improvement in this area could be expected. This is all the more important as an increase in UPS should only be considered as an actual increase if the improvement exceeds 24s (Goldberg et al., 2011).

One of the strengths of this study is, that physical fitness was measured with additional test besides those commonly used in similar studies, that is, sit-to-stand, and uni-pedal stance test, to ensure a detailed look at the effects of the program evaluated.

Looking at the significantly changed outcomes, it is evident that significant differences between IG and CG were achieved in isometric strength as well as range of motion. Differences between IG and CG show that the IG increased isometric strength to a little extent but more important we can notice a decrease in CG. The increase in muscular strength could be due to the fact that positive adaptations in healthy elderly subjects can be expected even at low intensities (Taaffe et al., 1996; Takarada and Ishii, 2002; Watanabe et al., 2014). Regarding the developments in CG, it can be said that decreases in the domain of isometric strength within 3 months are highly likely and can also be found in other studies (Henwood and Taaffe, 2008; Park and Yim, 2016). In particular, when physical activity is lacking, as reported by Doherty (2001), muscle strength decreases significantly, becoming functionally important in women in the 7th decade of life, which is consistent with findings on the loss of muscle strength in inactive people of age (Goodpaster et al., 2006; Forrest et al., 2007; Henwood and Taaffe, 2008).

The significant increase in shoulder and hip joint range of motion can be attributed in part to the fact that flexibility can benefit from resistance training (Barbosa et al., 2002; Monteiro et al., 2008; Carneiro et al., 2015) as well as stretching as applied in the program (Bandy et al., 1997; Feland et al., 2001; Batista et al., 2009). As far as stretching is concerned, it can be assumed that, in addition to the novelty of the exercises, the intensity may have been more appropriate, since the feeling of exertion during stretching is often difficult to assess subjectively, that is, no overload or heavy strain might have been noticed (Lim and Park, 2017).

Surprisingly, no significant differences in the outcomes that have been influenced by the intervention were found with the evaluation of the IG subgroups, which indicates that the results within the domains of muscular strength, and flexibility are not linked onto frequency of exercise or the duration of it.

The results of this study should be interpreted considering the following limitations. Since we did not assess rating of perceived exertion after each session to control for the exercise intensity, it remains the possibility that the recommended exercise intensity was not achieved by all participants. To improve comparability and reproducibility, we recommend that further exercise studies using modern technology (e.g., smartphone- or tablet-based apps) report both markers of external load and internal load to appropriately characterize the exercise intensity (Gronwald et al., 2019; Herold et al., 2020). Given that the duration of the intervention is an important factor contributing to its success (Silva et al., 2014), the short intervention duration of 14 weeks could be another potential confounder. Lastly, our findings can be only generalized to the group of very fit women over 60 years of age, whereas the effects might be even more pronounced in older and/or less fit participants given the promising findings of another study in the group of frail older adults (Jungreitmayr et al., 2021).

\section{Take Home Message}

Since the adherence to our app-based physical exercise program was relatively high, physical exercise programs delivered by modern technologies could be a promising option allowing older individuals to better incorporate physical exercise and physical activity in their everyday life, thus make a valuable contribution to prevent (slow down) the age-related decline of muscular strength or range of motion. Our findings suggest that our app-based physical training program is a promising option to counteract the decline in physical fitness and mobility and thus is well-situated to enable women over 60 years to achieve a physically active lifestyle.

\section{DATA AVAILABILITY STATEMENT}

The datasets presented in this article are not readily available because of data privacy regulations. Requests to access the datasets should be directed to sonja.jungreitmayr@plus.ac.at.

\section{AUTHOR CONTRIBUTIONS}

SJ: conceptualization, formal analysis, investigation, writingoriginal draft preparation, and visualization. SJ (data of all testing carried out in practice), CK, and VV (usage data): data curation. SR-D and SJ: writing-review and editing. SR-D: supervision. VV: project administration and funding acquisition. All authors have read and agreed to the published version of the manuscript.

\section{FUNDING}

The co-operative project, "Fit in einen neuen Lebensabschnitt mit neuen Technologien-AAL-Testregion Salzburg/Wien (fit4AAL)" with the grant number 862035, was funded by the 
Austrian Federal Ministry for Transport, Innovation and Technology under the research program benefit.

\section{ACKNOWLEDGMENTS}

For the development of the exercise modules and the conduction of the field trial, the Department of Sport and

\section{REFERENCES}

Alexander, N. B., Gross, M. M., Medell, J. L., and Hofmeyer, M. R. (2001). Effects of functional ability and training on chair-rise biomechanics in older adults. J. Gerontol. 56:M538. doi: 10.1093/gerona/56.9.M538

Arney, B. E., Glover, R., Fusco, A., Cortis, C., de Koning, J. J., van Erp, T., et al. (2019). Comparison of RPE (rating of perceived exertion) scales for session RPE. Int. J. Sports Physiol. Perform. 14, 994-996. doi: 10.1123/ ijspp.2018-0637

Ayala, F., Sainz de Baranda, P., De Ste, C. M., and Santonja, F. (2012). Reproducibility and concurrent validity of hip joint angle test for estimating hamstring flexibility in recreationally active young men. The. J. Strength Cond. Res. 26, 2372-2382. doi: 10.1519/JSC.0b013e31823dble2

Bandy, W. D., Irion, J. M., and Briggler, M. (1997). The effect of time and frequency of static stretching on flexibility of the hamstring muscles. Phys. Ther. 77, 1090-1096. doi: $10.1093 / \mathrm{ptj} / 77.10 .1090$

Barbosa, A. R., Santarém, J. M., Jacob Filho, W., and Marucci, M. D. F. N. (2002). Effects of resistance training on the sit-and-reach test in elderly women. J. Strength Cond. Res. 16, 14-18

Bartrow, K. (2012). Untersuchen und Befunden in der Physiotherapie. Germany: Springer.

Batista, L. H., Vilar, A. C., De Almeida Ferreira, J. J., Rebelatto, J. R., and Salvini, T. F. (2009). Active stretching improves flexibility, joint torque, and functional mobility in older women. Am. J. Phys. Med. Rehabil. 88, 815-822. doi: 10.1097/PHM.0b013e3181b72149

Bemben, D. A., Fetters, N. L., Bemben, M. G., Nabavi, N., and Koh, E. T. (2000). Musculoskeletal responses to high-and low-intensity resistance training in early postmenopausal women. Med. Sci. Sports Exerc. 32, 1949-1957. doi: 10.1097/00005768-200011000-00020

Bennell, K., Dobson, F., and Hinman, R. (2011). Measures of physical performance assessments: self-paced walk test (SPWT), stair climb test (SCT), six-minute walk test (6MWT), chair stand test (CST), timed up and go (TUG), sock test, lift and carry test (LCT), and car task. Arthritis Care Res. 63, S350-S370. doi: $10.1002 /$ acr.20538

Bohannon, R. W. (2019). Grip strength: an indispensable biomarker for older adults. Clin. Interv. Aging 14, 1681-1691. doi: 10.2147/CIA.S194543

Boutron, I., Altman, D. G., Moher, D., Schulz, K. F., and Ravaud, P. (2017). CONSORT statement for randomized trials of non-pharmacologic treatments: a 2017 update and a CONSORT extension for non-pharmacologic trial abstracts. Ann. Intern. Med. 167, 40-47. doi: 10.7326/M17-0046

Buckinx, F., Croisier, J. L., Reginster, J. Y., Dardenne, N., Beaudart, C., Slomian, J., et al. (2017). Reliability of muscle strength measures obtained with a handheld dynamometer in an elderly population. Clin. Physiol. Funct. Imaging 37, 332-340. doi: $10.1111 /$ cpf. 12300

Cadore, E. L., Pinto, R. S., Bottaro, M., and Izquierdo, M. (2014). Strength and endurance training prescription in healthy and frail elderly. Aging Dis. 5, 183-195. doi: 10.14336/AD.2014.0500183

Carneiro, N. H., Ribeiro, A. S., Nascimento, M. A., Gobbo, L. A., Schoenfeld, B. J., Achour Júnior, A., et al. (2015). Effects of different resistance training frequencies on flexibility in older women. Clin. Interv. Aging 10, 531-538. doi: 10.2147/CIA.S77433

Chao, D., Foy, C. G., and Farmer, D. (2000). Exercise adherence among older adults: challenges and strategies. Control. Clin. Trials 21, S212-S217. doi: 10.1016/S0197-2456(00)00081-7

Cohen, J. (1988). Statistical Power Analysis for the Behavioral Sciences. 2nd $E d n$. New Jersey: Lawrence Erlbaum Associates Inc.
Exercise Science of the Paris Lodron Universität Salzburg, and Salzburg Research want to thank their additional consortium partners: MyBodyCoach, bit media e-solutions $\mathrm{GmbH}$, SMART ASSETS Development GmbH, 50plus GmbH, Salzburg AG, Care Consulting (Sonja Schiff), Wirtschaftsuniversität Wien (Forschungsinstitut für Altersökonomie). We additionally thank all users in Salzburg and Vienna for their participation.

Colado, J. C., García-Massó, X., Pellicer, M., Alakhdar, Y., Benavent, J., and Cabeza-Ruiz, R. (2010). A comparison of elastic tubing and isotonic resistance exercises. Int. J. Sports Med. 31, 810-817. doi: 10.1055/s-0030-1262808

Collado-Mateo, D., Lavín-Pérez, A. M., Peñacoba, C., Del Coso, J., Leyton-Román, M., Luque-Casado, A., et al. (2021). Key factors associated with adherence to physical exercise in patients with chronic diseases and older adults: An umbrella review. Int. J. Environ. Res. Public Health 18:2023. doi: $10.3390 /$ ijerph 18042023

Corbin, C. B., and Lindsey, R. (1997). Concepts of Physical Fitness. Active Lifestyles for Wellness. 14 Edn. New York: McGraw-Hill.

Corbin, C. B., Pangrazi, R. P., and Franks, B. D. (2000). Definitions: Health, fitness, and physical activity. United States: President's Council on Physical Fitness and Sports.

Csuka, M., and McCarty, D. J. (1985). Simple method for measurement of lower extremity muscle strength. Am. J. Med. 78, 77-81. doi: 10.1016/0002-9343(85)90465-6

Davis, J. C., Robertson, M. C., Ashe, M. C., Liu-Ambrose, T., Khan, K. M., and Marra, C. A. (2010). Does a home-based strength and balance programme in people aged $\geq 80$ years provide the best value for money to prevent falls? A systematic review of economic evaluations of falls prevention interventions. Br. J. Sports Med. 44, 80-89. doi: 10.1136/ bjsm.2008.060988

Day, M. L., McGuigan, M. R., Brice, G., and Foster, C. (2004). Monitoring exercise intensity during resistance training using the session RPE scale. J. Strength Cond. Res. 18, 353-358. doi: 10.1519/r-13113.1

De Resende-Neto, A., Do Nascimento, M., Da Silva, D., Netto, R., De Santana, J., and Silva, M. (2019). Effects of multicomponent training on functional fitness and quality of life in older women: A randomized controlled trial. Int. J. Sport Exerc. Med. 5:126. doi: 10.23937/2469-5718/1510126

Dias, M. R. C., Simão, R., Saavedra, F. J. F., Buzzachera, C. F., and Fleck, S. (2018). Self-selected training load and RPE During resistance and aerobic training Among recreational exercisers. Percept. Mot. Skills 125, 769-787. doi: $10.1177 / 0031512518774461$

Doherty, T. J. (2001). The influence of aging and sex on skeletal muscle mass and strength. Curr. Opinion Clin. Nut. Meta. Care 4, 503-508. doi: 10.1097/00075197-200111000-00007

Duchowny, K. A., Peterson, M. D., and Clarke, P. J. (2017). Cut points for clinical muscle weakness Among older Americans. Am. J. Prev. Med. 53, 63-69. doi: 10.1016/j.amepre.2016.12.022

Elsangedy, H. M., Krause, M. P., Krinski, K., Alves, R. C., Hsin Nery Chao, C., and da Silva, S. G. (2013). Is the self-selected resistance exercise intensity by older women consistent With the American College of Sports Medicine guidelines to improve muscular fitness. J. Strength Cond. Res. 27, 1877-1884. doi: $10.1519 /$ JSC.0b013e3182736cfa

Feland, J. B., Myrer, J. W., Schulthies, S. S., Fellingham, G. W., and Measom, G. W. (2001). The effect of duration of stretching of the hamstring muscle Group for Increasing Range of motion in people aged 65 years or older. Phys. Ther. 81, 1110-1117. doi: $10.1093 / \mathrm{ptj} / 81.5 .1110$

Fennell, C., Peroutky, K., and Glickman, E. (2016). Effects of supervised training compared to unsupervised training on physical activity, muscular endurance, and cardiovascular parameters. MOJ Ortho. Rheumatol. 5:00184. doi: 10.15406/ mojor.2016.05.00184

Fess, F. (1992). "Grip strength," Clinical Assessment Recommendations. 2nd Edn, $41-45$.

Focht, B. C. (2007). Perceived exertion and training load during self-selected and imposed-intensity resistance exercise in untrained women. J. Strength Cond. Res. 21, 183-187. doi: 10.1519/00124278-200702000-00033 
Forrest, K. Y., Zmuda, J. M., and Cauley, J. A. (2007). Patterns and correlates of muscle strength loss in older women. Gerontology 53, 140-147. doi: $10.1159 / 000097979$

Fragala, M. S., Cadore, E. L., Dorgo, S., Izquierdo, M., Kraemer, W. J., Peterson, M. D., et al. (2019). Resistance training for older adults: position statement From the National Strength and conditioning association. J. Strength Cond. Res. 33, 2019-2052. doi: 10.1519/JSC.0000000000003230

Gao, Z., Lee, J. E., McDonough, D. J., and Albers, C. (2020). Virtual reality exercise as a coping strategy for health and wellness promotion in older adults during the COVID-19 pandemic. J. Clin. Med. 9:1986. doi: 10.3390/jcm9061986

Garber, C. E., Blissmer, B., Deschenes, M. R., Franklin, B. A., Lamonte, M. J., Lee, I.-M., et al. (2011). Quantity and quality of exercise for developing and maintaining cardiorespiratory, musculoskeletal, and neuromotor fitness in apparently healthy adults: guidance for prescribing exercise. Am. College Sports Med. 43, 1334-1359. doi: 10.1249/MSS.0b013e318213fefb

Geraedts, H. A., Dijkstra, H., Zhang, W., Ibarra, F., Far, I. K., Zijlstra, W., et al. (2021). Effectiveness of an individually tailored home-based exercise programme for pre-frail older adults, driven by a tablet application and mobility monitoring: a pilot study. Eur. Rev. Aging Phys. Act. 18, 1-9. doi: 10.1186/s11556-021-00264-y

Geraedts, H., Zijlstra, A., Bulstra, S. K., Stevens, M., and Zijlstra, W. (2013). Effects of remote feedback in home-based physical activity interventions for older adults: A systematic review. Patient Educ. Couns. 91, 14-24. doi: 10.1016/j.pec.2012.10.018

Geraedts, H. A., Zijlstra, W., Zhang, W., Bulstra, S., and Stevens, M. (2014). Adherence to and effectiveness of an individually tailored home-based exercise program for frail older adults, driven by mobility monitoring: design of a prospective cohort study. BMC Pub. Health 14, 1-7. doi: 10.1186/14712458-14-570

Göeken, L. N., and Hof, A. L. (1994). Instrumental straight-leg raising: results in patients. Arch. Phys. Med. Rehabil. 75, 470-477. doi: 10.1016/0003-9993(94)90174-0

Goldberg, A., Casby, A., and Wasielewski, M. (2011). Minimum detectable change for single-leg-stance-time in older adults. Gait Posture 33, 737-739. doi: 10.1016/j.gaitpost.2011.02.020

Goodpaster, B. H., Park, S. W., Harris, T. B., Kritchevsky, S. B., Nevitt, M., Schwartz, A. V., et al. (2006). The loss of skeletal muscle strength, mass, and quality in older adults: The health, aging and body composition study. J. Gerontol. 61, 1059-1064. doi: 10.1093/gerona/61.10.1059

Granacher, U., Muehlbauer, T., Gschwind, Y., Pfenninger, B., and Kressig, R. (2014). Diagnostik und Training von Kraft und Gleichgewicht zur Sturzprävention im Alter. Z. Gerontol. Geriatr. 47, 513-526. doi: 10.1007/ s00391-013-0509-5

Gronwald, T., De Bem Alves, A. C., Murillo-Rodríguez, E., Latini, A., Schuette, J., and Budde, H. (2019). Standardization of exercise intensity and consideration of a dose-response is essential. Commentary on "exercise-linked FNDC5/ irisin rescues synaptic plasticity and memory defects in Alzheimer's models", by Lourenco et al., published 2019 in nature medicine. J. Sports Health Sci. 8, 353-354. doi: 10.1016/j.jshs.2019.03.006

Grundy, E. M., and Murphy, M. (2017). "Population ageing in Europe," in Oxford Textbook of Geriatric Medicine. eds. M. Jean-Pierre, B. B. Lynn, C. Martin Finbarr and D. Walston Jeremy (United Kingdom: Oxford University Press), $11-18$.

Guralnik, J. M., Simonsick, E. M., Ferrucci, L., Glynn, R. J., Berkman, L. F., Blazer, D. G., et al. (1994). A short physical performance battery assessing lower extremity function: association with self-reported disability and prediction of mortality and nursing home admission. J. Gerontol. 49, M85-M94. doi: 10.1093/geronj/49.2.M85

Halbertsma, J. P., Göeken, L. N., Hof, A. L., Groothoff, J. W., and Eisma, W. H. (2001). Extensibility and stiffness of the hamstrings in patients with nonspecific low back pain. Arch. Phys. Med. Rehabil. 82, 232-238. doi: 10.1053/ apmr.2001.19786

Hawley-Hague, H., Horne, M., Skelton, D., and Todd, C. (2016). Review of how we should define (and measure) adherence in studies examining older adults' participation in exercise classes. BMJ Open 6:e011560. doi: 10.1136/ bmjopen-2016-011560

Hazell, T., Kenno, K., and Jakobi, J. (2007). Functional benefit of power training for older adults. J. Aging Phys. Act. 15, 349-359. doi: 10.1123/ japa.15.3.349
Henwood, T. R., and Taaffe, D. R. (2008). Detraining and retraining in older adults following long-term muscle power or muscle strength specific training. J. Gerontol. 63, 751-758. doi: 10.1093/gerona/63.7.751

Herda, A. A., McKay, B. D., Herda, T. J., Costa, P. B., Stout, J. R., and Cramer, J. T. (2020). Changes in strength, mobility, and body composition following self-selected exercise in older adults. J. Aging Phys. Act. 29, 17-26. doi: $10.1123 /$ japa.2019-0468

Herold, F., Törpel, A., Hamacher, D., Budde, H., and Gronwald, T. (2020). A discussion on different approaches for prescribing physical interventions four roads Lead to Rome, but which one should we choose? J. Personal. Med. 10:55. doi: 10.3390/jpm10030055

Hislop, H., Avers, D., and Brown, M. (2013). Daniels and Worthingham's Muscle Testing-E-Book: Techniques of Manual Examination and Performance Testing. Amsterdam: Elsevier Health Sciences.

Hunter, G. R., Wetzstein, C. J., Mclafferty, C. L. Jr., Zuckerman, P. A., Landers, K. A., and Bamman, M. M. (2001). High-resistance versus variable-resistance training in older adults. Med. Sci. Sports Exerc. 33, 1759-1764. doi: 10.1097/00005768-200110000-00022

Innes, E. (1999). Handgrip strength testing: a review of the literature. Aust. Occup. Ther. J. 46, 120-140. doi: 10.1046/j.1440-1630.1999.00182.x

Izquierdo, M., Merchant, R., Morley, J., Anker, S., Aprahamian, I., Arai, H., et al. (2021). International exercise recommendations in older adults (ICFSR): expert consensus guidelines. J. Nutr. Health Aging 25, 824-853. doi: 10.1007/ s12603-021-1665-8

Jenks, G. F. (1967). The data model concept in statistical mapping. Int. Yearbook Carto. 7, 186-190.

Jones, C. J., Rikli, R. E., and Beam, W. C. (1999). A 30-s chair-stand test as a measure of lower body strength in community-residing older adults. Res. Q. Exerc. Sport 70, 113-119. doi: 10.1080/02701367.1999.10608028

Jungreitmayr, S., Ring-Dimitriou, S., Trukeschitz, B., Eisenberg, S., and Schneider, C. (2021). Effects of an information and communication technology-based fitness program on strength and balance in female home care service users. Int. J. Environ. Res. Public Health 18:7955. doi: 10.3390/ijerph18157955

Kalapotharakos, V. I., Michalopoulos, M., Tokmakidis, S. P., Godolias, G., and Gourgoulis, V. (2005). Effects of a heavy and a moderate resistance training on functional performance in older adults. J. Strength Cond. Res. 19, 652-657. doi: $10.1519 / 15284.1$

Kelders, S. M., Kok, R. N., Ossebaard, H. C., and Van Gemert-Pijnen, J. E. (2012). Persuasive system design does matter: a systematic review of adherence to web-based interventions. J. Med. Internet Res. 14:e152. doi: 10.2196/ jmir.2104

Kilpatrick, M., Newsome, A. N., Foster, C., Robertson, R., and Green, M. (2020). Scientific rationale for RPE use in fitness assessment and exercise participation. ACSMs Health Fit J. 24, 24-30. doi: 10.1249/ FIT.0000000000000587

Kim, E.-Y., Kim, S.-Y., and Oh, D.-W. (2012). Pelvic floor muscle exercises utilizing trunk stabilization for treating postpartum urinary incontinence: randomized controlled pilot trial of supervised versus unsupervised training. Clin. Rehabil. 26, 132-141. doi: 10.1177/0269215511411498

Knickman, J. R., and Snell, E. K. (2002). The 2030 problem: caring for aging baby boomers. Health Serv. Res. 37, 849-884. doi: 10.1034/j.1600-0560. 2002.56.x

Kolber, M. J., and Cleland, J. A. (2005). Strength testing using hand-held dynamometry. Phys. Ther. Rev. 10, 99-112. doi: 10.1179/108331905X55730

Kraemer, W. J., and Ratamess, N. A. (2004). Fundamentals of resistance training: progression and exercise prescription. Med. Sci. Sports Exerc. 36, 674-688. doi: 10.1249/01.MSS.0000121945.36635.61

Kramer, J. B., Stone, M. H., O’Bryant, H. S., Conley, M. S., Johnson, R. L., Nieman, D. C., et al. (1997). Effects of single vs. multiple sets of weight training: impact of volume, intensity, and variation. J. Strength Condition. Res. 11, 143-147.

Krause, D. A., Neuger, M. D., Lambert, K. A., Johnson, A. E., DeVinny, H. A., and Hollman, J. H. (2014). Effects of examiner strength on reliability of hip-strength testing using a handheld dynamometer. J. Sport Rehabil. 23, 56-64. doi: 10.1123/JSR.2012-0070

Lacroix, A., Hortobágyi, T., Beurskens, R., and Granacher, U. (2017). Effects of supervised vs. unsupervised training programs on balance and muscle strength in older adults: A systematic review and meta-analysis. Sports Med. 47, 2341-2361. doi: 10.1007/s40279-017-0747-6 
Lesinski, M., Hortobágyi, T., Muehlbauer, T., Gollhofer, A., and Granacher, U. (2015). Dose-response relationships of balance training in healthy young adults: a systematic review and meta-analysis. Sports Med. 45, 557-576. doi: $10.1007 /$ s40279-014-0284-5

Lim, W., and Park, H. (2017). No significant correlation between the intensity of static stretching and subject's perception of pain. J. Phys. Ther. Sci. 29:1856. doi: $10.1589 /$ jpts.29.1856

Lutz, W., Goujon, A., Kc, S., Stonawski, M., and Stilianakis, N. (2018). Demographic and Human Capital Scenarios for the 21st Century: 2018 Assessment for 201 Countries. Luxembourg: Publications Office of the European Union.

Marshall, P. W. M., Cashman, A., and Cheema, B. S. (2011). A randomized controlled trial for the effect of passive stretching on measures of hamstring extensibility, passive stiffness, strength, and stretch tolerance. J. Sci. Med. Sport 14, 535-540. doi: 10.1016/j.jsams.2011.05.003

Martins, W. R., De Oliveira, R. J., Carvalho, R. S., De Oliveira, D. V., Da Silva, V. Z. M., and Silva, M. S. (2013). Elastic resistance training to increase muscle strength in elderly: A systematic review with meta-analysis. Arch. Gerontol. Geriatr. 57, 8-15. doi: 10.1016/j.archger.2013.03.002

Mehra, S., Van den Helder, J., Kröse, B. J. A., Engelbert, R. H. H., Weijs, P. J. M., and Visser, B. (2021). The Use of a Tablet to Increase Older Adults' Exercise Adherence. Cham: Springer International Publishing.

Mentiplay, B. F., Perraton, L. G., Bower, K. J., Adair, B., Pua, Y.-H., Williams, G. P., et al. (2015). Assessment of lower limb muscle strength and power using hand-held and fixed dynamometry: a reliability and validity study. PLoS One 10:e0140822. doi: 10.1371/journal.pone.0140822

Monteiro, W. D., Simão, R., Polito, M. D., Santana, C. A., Chaves, R. B., Bezerra, E., et al. (2008). Influence of strength training on adult Women's flexibility. J. Strength Cond. Res. 22, 672-677. doi: 10.1519/JSC.0b013e31816a5d45

Müller, C., Lautenschläger, S., Dörge, C., and Voigt-Radloff, S. (2021). A feasibility study of a home-based lifestyle-integrated physical exercise training and home modification for community-living older people (part 2): the FIT-athome fall prevention program. Disabil. Rehabil. 43, 1380-1390. doi: 10.1080/09638288.2019.1700564

Murtagh, K. N., and Hubert, H. B. (2004). Gender differences in physical disability among an elderly cohort. Am. J. Public Health 94, 1406-1411. doi: 10.2105/AJPH.94.8.1406

Nakamura, Y., Tanaka, K., Yabushita, N., Sakai, T., and Shigematsu, R. (2007). Effects of exercise frequency on functional fitness in older adult women. Arch. Gerontol. Geriatr. 44, 163-173. doi: 10.1016/j.archger.2006.04.007

Netz, Y., Yekutieli, Z., Arnon, M., Argov, E., Tchelet, K., Benmoha, E., et al. (2021). Personalized exercise programs based upon remote assessment of motor fitness: A pilot study among healthy people aged 65 years and older. Gerontology 67, 1-15. doi: 10.1159/000517918

Neumann, S., Meidert, U., Barberà-Guillem, R., Poveda-Puente, R., and Becker, H. (2018). Effects of an exergame software for older adults on fitness, activities of daily living performance, and quality of life. Games Health J. 7, 341-346. doi: $10.1089 /$ g 4 h.2017.0079

Nogueira, A. C., De Resende Neto, A. G., Santos, J. C. A., Da Silva Chaves, L. M., Azevêdo, L. M., Teixeira, C. V. L. S., et al. (2017). Effects of a multicomponent training protocol on functional fitness and quality of life of physically active older women. Motricidade 13, 86-93.

Page, P. (2012). Current concepts in muscle stretching for exercise and rehabilitation. Int. J. Sports Phys. Ther. 7, 109-119.

Park, J., and Yim, J. (2016). A new approach to improve cognition, muscle strength, and postural balance in community-dwelling elderly with a $3 \mathrm{D}$ virtual reality kayak program. Tohoku J. Exp. Med. 238, 1-8. doi: 10.1620/ tjem.238.1

Picorelli, A. M. A., Pereira, D. S., Felício, D. C., Dos Anjos, D. M., Pereira, D. A. G., Dias, R. C., et al. (2014). Adherence of older women with strength training and aerobic exercise. Clin. Interv. Aging 9:323. doi: 10.2147/CIA.S54644

Richardson, D. L., Duncan, M. J., Jimenez, A., Juris, P. M., and Clarke, N. D. (2019). Effects of movement velocity and training frequency of resistance exercise on functional performance in older adults: a randomised controlled trial. Eur. J. Sport Sci. 19, 234-246. doi: 10.1080/17461391.2018.1497709

Rikli, R. E., and Jones, C. J. (1999). Functional fitness normative scores for community-residing older adults, ages 60-94. J. Aging Phys. Act. 7, 162-181. doi: 10.1123/japa.7.2.162

Rikli, R. E., and Jones, C. J. (2013). Senior Fitness Test Manual. United Kingdom: Human Kinetics.
Rooney, E. M. (1993). Exercise for older patients: why it's worth your effort. Geriatrics 48, 68-71.

Scheffé, H. (1970). The Analysis of Variance. 6th Edn. Canada: Wiley \& Sons, Inc.

Schutzer, K. A., and Graves, B. S. (2004). Barriers and motivations to exercise in older adults. Prev. Med. 39, 1056-1061. doi: 10.1016/j.ypmed.2004.04.003

Silva, N. L., Oliveira, R. B., Fleck, S. J., Leon, A. C. M. P., and Farinatti, P. (2014). Influence of strength training variables on strength gains in adults over 55 years-old: A meta-analysis of dose-response relationships. J. Sci. Med. Sport 17, 337-344. doi: 10.1016/j.jsams.2013.05.009

Sousa, N., Mendes, R., Silva, S., Garrido, N., Abrantes, C., and Reis, V. (2013). Effects of resistance and multicomponent training on body composition and physical fitness of institutionalized elderly women. Br. J. Sports Med. 47, e3-e48. doi: 10.1136/bjsports-2013-092558.52

Springer, B. A., Marin, R., Cyhan, T., Roberts, H., and Gill, N. W. (2007). Normative values for the Unipedal stance test with eyes open and closed J. Geriatr. Phys. Ther. 30, 8-15. doi: 10.1519/00139143-200704000-00003

Stojanović, M. D. M., Mikić, M. J., Milošević, Z., Vuković, J., Jezdimirović, T., and Vučetić, V. (2021). Effects of chair-based, low-load elastic band resistance training on functional fitness and metabolic biomarkers in older women. J. Sports Sci. Med. 20, 133-141. doi: 10.52082/jssm.2021.133

Storer, T. W., Dolezal, B. A., Berenc, M. N., Timmins, J. E., and Cooper, C. B. (2014). Effect of supervised, Periodized exercise training vs. self-directed training on lean body mass and other fitness variables in health Club members. J. Strength Cond. Res. 28, 1995-2006. doi: 10.1519/JSC.0000000000000331

Suzuki, M., Ohyama, N., Yamada, K., and Kanamori, M. (2002). The relationship between fear of falling, activities of daily living and quality of life among elderly individuals. Nurs. Health Sci. 4, 155-161. doi: 10.1046/j.1442-2018. 2002.00123.x

Taaffe, D. R., Duret, C., Wheeler, S., and Marcus, R. (1999). Once-weekly resistance exercise improves muscle strength and neuromuscular performance in older adults. J. Am. Geriatr. Soc. 47, 1208-1214. doi: 10.1111/j.1532-5415.1999. tb05201.x

Taaffe, D., Pruitt, L., Pyka, G., Guido, D., and Marcus, R. (1996). Comparative effects of high-and low-intensity resistance training on thigh muscle strength, fiber area, and tissue composition in elderly women. Clin. Physiol. 16, 381-392. doi: 10.1111/j.1475-097X.1996.tb00727.x

Takarada, Y., and Ishii, N. (2002). Effects of low-intensity resistance exercise with short interset rest period on muscular function in middle-aged women. J. Strength Cond. Res. 16, 123-128.

Tanaka, H. (2009). Habitual exercise for the elderly. Fam. Comm. Health 32, S57-S65. doi: 10.1097/01.FCH.0000342840.43724.ce

Thiebaud, R. S., Funk, M. D., and Abe, T. (2014). Home-based resistance training for older adults: a systematic review. Geriatr Gerontol Int 14, 750-757. doi: 10.1111 /ggi.12326

Treacy, D., and Hassett, L. (2018). The short physical performance battery. J. Physiother. 64:61. doi: 10.1016/j.jphys.2017.04.002

Trukeschitz, B. M., Schneider, C., Jungreitmayr, S., and Eisenberg, S. (2019). Fit-mit-ILSE Feldtest: Design, Rekrutierung und Übersicht über die TeilnehmerInnen zu Beginn des Feldtests. Austria: Wirtschaftsuniversität Wien.

Valenzuela, T., Okubo, Y., Woodbury, A., Lord, S. R., and Delbaere, K. (2018). Adherence to technology-based exercise programs in older adults: a systematic review. J. Geriatr. Phys. Ther. 41, 49-61. doi: 10.1519/JPT.0000000000000095

Van Blommestein, A. S., MaCrae, S., Lewis, J., and Morrissey, M. (2012). Reliability of measuring thoracic kyphosis angle, lumbar lordosis angle and straight leg raise with an inclinometer. Open Spine J. 4, 10-15. doi: 10.2174/1876532701204010010

Van den Helder, J., Mehra, S., van Dronkelaar, C., Ter Riet, G., Tieland, M., Visser, B., et al. (2020). Blended home-based exercise and dietary protein in community-dwelling older adults: a cluster randomized controlled trial. J. Cachexia. Sarcopenia Muscle 11, 1590-1602. doi: 10.1002/jcsm.12634

Van Het Reve, E., Silveira, P., Daniel, F., Casati, F., and De Bruin, E. D. (2014). Tablet-based strength-balance training to motivate and improve adherence to exercise in independently living older people: part 2 of a phase II preclinical exploratory trial. J. Med. Internet Res. 16:e159. doi: 10.2196/jmir.3055

Venek, V., Kremser, W., and Stöggl, T. (2021). Towards a live feedback training system: interchangeability of Orbbec Persee and Microsoft Kinect for exercise monitoring. Designs 5:30. doi: 10.3390/designs5020030

Wang, Y.-C., Bohannon, R. W., Li, X., Sindhu, B., and Kapellusch, J. (2018). Hand-grip strength: normative reference values and equations for individuals 
18 to 85 years of age residing in the United States. J. Ortho. Sports Phy. Ther. 48, 685-693. doi: 10.2519/jospt.2018.7851

Watanabe, Y., Madarame, H., Ogasawara, R., Nakazato, K., and Ishii, N. (2014). Effect of very low-intensity resistance training with slow movement on muscle size and strength in healthy older adults. Clin. Physiol. Funct. Imaging 34, 463-470. doi: $10.1111 /$ cpf.12117

WHO (2020). Decade of healthy ageing: baseline report. Geneva: World Health Organization.

Wieben, K., and Falkenberg, B. (2001). Muskelfunktion: Prüfung und klinische Bedeutung. Germany: Georg Thieme Verlag.

Williams, N. (2017). The Borg rating of perceived exertion (RPE) scale. Occup. Med. 67, 404-405. doi: 10.1093/occmed/kqx063

Yang, Y.-P., Lin, H.-C., and Chen, K.-M. (2019). Functional fitness in older adults: A systematic review and meta-analysis. Topic Geriat. Rehab. 35, 238-247. doi: 10.1097/TGR.0000000000000241

Yardley, L., Bishop, F. L., Beyer, N., Hauer, K., Kempen, G. I. J. M., Piot-Ziegler, C., et al. (2006). Older People's views of falls-prevention interventions in six European countries. Gerontologist 46, 650-660. doi: 10.1093/geront/46.5.650

Yerrakalva, D., Yerrakalva, D., Hajna, S., and Griffin, S. (2019). Effects of mobile health app interventions on sedentary time, physical activity, and fitness in older adults: systematic review and meta-analysis. J. Med. Internet Res. 21:e14343. doi: $10.2196 / 14343$

Zaleski, A. L., Taylor, B. A., Panza, G. A., Wu, Y., Pescatello, L. S., Thompson, P. D., et al. (2016). Coming of age: considerations in the prescription of exercise for older adults. Methodist Debakey Cardiovasc. J. 12, 98-104. doi: 10.14797/ mdcj-12-2-98

Zander, A. (2018). Kraftmessgerät micro FET 2-Objektiv die Kraft messen. Physiopraxis 16, 34-35. doi: 10.1055/a-0632-9905

Conflict of Interest: CK and VV were employed by company Salzburg Research Forschungsgesellschaft mbH. SJ is the owner of MyBodyCoach.

The remaining authors declare that the research was conducted in the absence of any commercial or financial relationships that could be construed as a potential conflict of interest.

Publisher's Note: All claims expressed in this article are solely those of the authors and do not necessarily represent those of their affiliated organizations, or those of the publisher, the editors and the reviewers. Any product that may be evaluated in this article, or claim that may be made by its manufacturer, is not guaranteed or endorsed by the publisher.

Copyright $\odot 2022$ Jungreitmayr, Kranzinger, Venek and Ring-Dimitriou. This is an open-access article distributed under the terms of the Creative Commons Attribution License (CC BY). The use, distribution or reproduction in other forums is permitted, provided the original author(s) and the copyright owner(s) are credited and that the original publication in this journal is cited, in accordance with accepted academic practice. No use, distribution or reproduction is permitted which does not comply with these terms. 